\title{
REDEFINISI MAKNA TRADISI BEGALAN OLEH SANGGAR SEKAR KANTIL DALAM RITUS PERNIKAHAN MASYARAKAT BANYUMAS
}

\section{REDEFINITION OF THE BEGALAN TRADITION MEANINGS BY SANGGAR SEKAR KANTIL IN THE MARRIAGE RITES IN THE BANYUMAS COMMUNITY}

\author{
Endri Apriliana Adi Wahyu, Nugroho Trisnu Brata \\ endri.a.a.w@gmail.com, trisnu_ntb2015@mail.unnes.ac.id \\ Jurusan Sosiologi dan Antropologi, Fakultas Ilmu Sosial \\ Universitas Negeri Semarang
}

Artikel diterima: 22 Oktober $2020 \quad$ Artikel direvisi: 9 November 2020 || Artikel disetujui: 13 November 2020

\begin{abstract}
ABSTRAK
Tradisi begalan adalah salah satu tradisi pernikahan yang ada pada masyarakat Kabupaten Banyumas yang sarat akan makna dan nasehat bagi pasangan pengantin yang baru saja menikah. Sanggar Sekar Kantil sebagai salah satu sanggar yang masih melestarikan sekaligus tempat bernaung bagi beberapa pelaku tradisi begalan yang ada di Kabupaten Banyumas memiliki pandangan baru terhadap tradisi begalan. Hasil penelitian menunjukan bahwa: 1) Proses pelaksanaan tradisi begalan oleh sanggar Sekar Kantil terdiri dari dua tahapan yaitu tahap persiapan dan tahap pelaksanaan. Tahap persiapan dilakukan oleh pelaku tradisi begalan untuk mempersiapkan segala sesuatu yang dibutuhkan dalam pelaksanaan tradisi begalan. Tahap pelaksaaan merupakan tahap dimana pelaku tradisi begalan melaksanakan pementasan tradisi begalan pada pernikahan masyarakat Banyumas. 2) Redefinisi makna tradisi begalan yang diberikan oleh sanggar Sekar Kantil terhadap tradisi begalan adalah pada arti tradisi begalan yang sebelumnya berasal dari kata begal yang artinya rampok menjadi besan gawa lantaran. Redefinisi juga diberikan kepada nama pelaku tradisi begalan yaitu danabau dan juru mertani serta penjelasan ubo rampe tradisi begalan yang dilaksanakan oleh sanggar Sekar kantil menggunakan sanepan atau othak athik gathuk.
\end{abstract}

Kata kunci: Tradisi Begalan, Makna, Sanggar

\section{ABSTRACT}

Begalan tradition is one of the marriage traditions that exist in the Banyumas Regency society which is full of meaning and advice for newly married brides. Sekar Kantil Studio as one of the studios that still preserves as well as acting as a shelter for a number of performers of the begalan tradition in Banyumas Regency has a new view of the begalan tradition. The results of the research show that: 1) The process of implementing the begalan tradition by the Sekar Kantil studio consists of two stages: the preparatory stage and the implementation stage. The preparatory stage is carried out by the performers of the begalan tradition to prepare everything needed in the implementation of the begalan tradition. The implementation stage is the stage where the performers of traditions carry out the performance of traditions at the Banyumas community wedding. 2) The redefinition of the meaning of the tradition given by the Sekar Kantil studio to the tradition is that the tradition is derived from the word "begal" which means "robber" into "besan gawa lantaran". Redefinition was also given to the names of performers of the begalan tradition, Danabau and Juru mertani, and also the explanation of the ubo rampe of the tradition carried out by the Sekar Kantil studio using sanepan or othak atihk gathuk.

Keywords: Begalan Tradition, Meaning, Studio

\section{PENDAHULUAN}

Indonesia merupakan salah satu negara yang memiliki banyak etnis, ras, suku bangsa, budaya dan agama yang tersebar di berbagai wilayah, sehingga tidak heran bahwa Indonesia mendapat julukan bangsa 
multikultural (Firtiani, 2012:74). Setiap daerah memiliki ciri khas yang membedakan dengan kebudayaan dan tradisi yang ada di daerah lain. Kebudayaan Indonesia berakar dari kebudayaan etnik (lokal) di Indonesia yang memiliki keragaman (Brata, 2016:10).

Banyaknya keanekaragaman budaya yang ada, salah satunya yaitu keanekaragaman seni tradisi. Menurut Hessterman (dalam Laksono, 2009:10) tradisi merupakan sebuah jalan bagi masyarakat untuk merumuskan dan menanggapi persoalan dasar dalam kebudayaan yaitu sebuah kesepakatan yang dicapai di masyarakat. Tradisi menampilkan tatanan bebas yang ada di atas tindakan yang aktual. Salah satu tradisi yang umum dilakukan pada masyarakat Jawa adalah slametan. Slametan menjadi bagian yang penting dalam kehidupan masyarakat, karena dalam setiap peristiwa yang terjadi seperti contohnya kelahiran, perkawinan, kematian dan sunatan, masyarakat Jawa akan mengadakan slametan. Mengadakan selamatan berarti melakukan upacara untuk memohon dan mendapatkan slamet dalam melakukan sesuatu yang dilakukan secara khusus (Newberry, 2013:62).

Tradisi pada saat ini membutuhkan banyak inovasi dan keluwesan untuk dapat diterima oleh masyarakat luas. Salah satu tradisi yang masih dilakukan oleh berbagai kalangan masyarakat di berbagai daerah adalah tradisi pernikahan. Pernikahan dalam masyarakat masih menjadi sebuah tujuan untuk mencapai kesempurnaan hidup. Di Jawa perkawinan menjadi pertanda dibentuknya sebuah somah baru yang segera akan memisahkan diri, baik secara ekonomi maupun tempat tinggal, lepas dari kelompok orang tua dan membentuk sebuah rumah tangga baru (Geertz, 1985:58).

Setiap daerah memiliki ciri khas dalam setiap pernikahan, yang berbeda satu daerah dengan daerah yang lainnya. Salah satu daerah yang masih mempertahankan tradisi unik dalam pernikahan adalah Kabupaten Banyumas di Jawa Tengah. Dalam upacara pernikahan yang ada pada masyarakat Banyumas, terdapat sebuah tradisi yang berbeda dan hanya diadakan pada pernikahan masyarakat Banyumas yaitu tradisi begalan. Menurut Karyono (2009:2) tradisi begalan adalah salah satu peninggalan budaya masyarakat Banyumas yang diwariskan secara turun-temurun sebagai salah satu syarat yang harus dilakukan dalam pernikahan anak sulung dengan anak sulung, anak bungsu mendapatkan anak bungsu, yang berfungsi sebagai ruwatan untuk menghindari rumah tangga dari petaka. Tradisi begalan juga digunakan sebagai pemberian nasihat perkawinan dan sebagai media transfer pengetahuan yang bermanfaat sebagai tuntunan dan pedoman dalam berperilaku sehari-hari setelah menikah bagi pasangan pengantin baru juga bagi pasangan suami-istri yang sudah lama berumah-tangga untuk kembali mengingatkan akan bagaimana penyelesaian masalah sesuai dengan apa yang telah diajarkan oleh orangtua (Priyanto, 2008:165).

Tradisi begalan dalam pelaksanaannya menggunakan ubo rampe atau perlengkapan yang terdiri dari peralatan rumah-tangga sebagai alat peraga untuk menjelaskan bagaimana kehidupan berumah-tangga, karena dalam setiap perlengkapan yang dibawa memiliki makna masing-masing. Dalam penyampaian tradisi begalan terdapat perbedaan makna dalam pelaksanaan pementasan yang menyesuaikan dengan latar belakang dari pelaku tradisi begalan. Makna yang disampaikan oleh pelaku tradisi begalan digunakan sebagai sarana untuk memberikan pengetahuan kepada masyarakat. Salah satu pelaku tradisi begalan yang memberikan pemaknaan adalah pelaku tradisi begalan dari sanggar Sekar Kantil. Pemaknaan yang diberikan berbeda dari yang ada sebelumnya karena menyesuaikan dengan perkembangan zaman yang didapatkan dari masukan berbagai pihak yang telah bekerjasama dengan sanggar Sekar Kantil.

Analisis kajian ini menggunakan teori fenomenologi yang dirumuskan oleh Hegel untuk menganalisis data hasil penelitian. Hegel (dalam Hamdanah: 2005) mengatakan bahwa istilah fenomenologi sebelumnya sering digunakan oleh Edmund Husserl dan Immanuel Kant. Kemudian Hegel mendefinisikan fenomenologi sebagai "pengetahuan sebagaimana pengetahuan tersebut tampil atau hadir terhadap kesadaran". Selain itu, fenomenologi dapat diartikan sebagai ilmu pengetahuan tentang penggambaran apa yang dilihat oleh 
seseorang, apa yang dirasakan dan diketahuinya dalam immediate awareness and experience-nya. Penekanan pada proses penggambaran ini akan membawa kita kepada upaya mengungkapkan "phenomenalconsciousness" atau kesadaran fenomenal melalui ilmu pengetahuan dasar filsafat menuju ke the absolute knowledge of the absolute (pengetahuan yang absolut tentang yang absolut). Menurut Brata (2008:17) antropologi fenomenologi muncul dalam perkembangan pendefinisian kebudayaan oleh para ahli antropologi yang akan digunakan untuk memecahkan persoalan yang muncul ketika antropologi melakukan proyek besar Cross-culture Comparison. Aliran ini mempunyai ciri penting yaitu menggunakan model-model yang berasal dari ilmu alam terutama biologi. Sehingga masyarakat atau kebudayaan dianggap sebagai organisme dimana unsur yang membentuknya saling berkaitan satu sama lain. Tujuan secara umum adalah untuk menghasilkan penyamaan tentang fenomena dengan menggunakan sarana metode perbandingan. Dalam filsafat fenomenologi, realitas merupakan totalitas pengalaman-pengalaman sadar yang mungkin ada. Segala sesuatu memberi kesan-kesan kepada kita sesuai dengan ciri khas subjek yang bersangkutan dan gejala yang diterima dalam kesadaran ini merupakan sebuah objek pengetahuan.

Penelitian ini memiliki tujuan untuk: 1) Memahami pelaksanaan tradisi begalan yang dilakukan oleh sanggar Sekar Kantil; 2) Memahami bagaimana sanggar Sekar Kantil memaknai tradisi begalan yang ada pada pernikahan masyarakat Banyumas. Hasil dari penelitian ini diharapkan dapat memberikan manfaat baik secara teoritis maupun secara praktis. Manfaat teoritis yang ingin dicapai dalam penelitian ini adalah: 1) Hasil penelitian ini diharapkan bermanfaat untuk memberikan pengetahuan sekaligus pemahaman mengenai tradisi pernikahan daerah yang ada di Indonesia. 2) Hasil penelitian ini diharapkan bermanfaat sebagai bahan rujukan penelitian yang sejenis. 3) Penelitian ini bermanfaat sebagai bahan pembelajaran Antropologi kelas XII materi "Sumber-sumber Kearifan Lokal dan Tradisi Lisan". Manfaat praktis yang ingin dicapai dalam penelitian ini adalah untuk memberikan informasi dan pengetahuan bagi pembaca dalam pembelajaran atau diskusi oleh masyarakat mengenai pemaknaan tradisi begalan pada pernikahan masyarakat Banyumas.

Berbagai macam tradisi yang ada di Indonesia memiliki keragaman dan keunikan yang berbeda dari satu daerah dengan daerah yang lain. Penelitian yang dilakukan oleh Kurniasih dan Brata (2015) menjelaskan mengenai tradisi ngenger yang dilakukan oleh masyarakat Desa Botoreco sebelum melakukan pernikahan menurut hukum negara. Salah satu calon mempelai, apakah calon suami atau calon istri terlebih dahulu mengabdi di rumah orang tua calon pasangannya selama beberapa waktu tertentu yang telah disepakati sebelumnya. Tujuan mengabdi pada keluarga calon mertua adalah untuk; mengetahui sikap dan kebiasaan keluarga calon suami atau istri, mengenal lingkungan calon suami atau istri, mendalami adat berumah-tangga, menunggu hari pernikahan, membantu pekerjaan calon mertua, mengetahui kesetiaan, dan melanjutkan sistem pertanian secara turun-temurun. Penelitian Utami (2016) mengkaji tentang budaya baradok yang dilakukan sebelum melakukan ikrar suci atau akad nikah untuk membersihkan segala kesan-kesan negatif yang ada dalam jiwa selama masa hidup.

Penelitian yang dilakukan oleh Kundharu Saddhono dan Kurniawan (2017) membahas mengenai makna yang terkandung dalam brenang kepang dan nilai-nilai agama dalam tradisi begalan sebagai pendidikan karakter untuk mahasiswa di Sekolah Menengah Atas (SMA) yang dapat diterapkan untuk proses belajar di sekolah khususnya nilai-nilai agama dan pedoman untuk belajar. Menurut Kholifah (2018) penggambaran elemen budaya dalam tradisi begalan dan strategi yang digunakan oleh budaya lokal melalui transferensi, parafrase dan terjemakan ikon. Terdapat 3 dari 5 kategori yang diusulkan yaitu material, sosial budaya serta sikap dan kebiasaan. Suroso dkk (2018) menjelaskan bahwa implikatur dari pengembangan karakter terdapat dalam kalimat "bajangsawan kaki penganten dan nini penganten" yang menggambarkan pengembangan dari karakter tradisi yang religius, kemerdekaan, kemandirian dan tanggung-jawab, dan masing-masing brenong kepang memiliki karakter masing-masing yang 
positif seperti kesuburan dan kemakmuran yang disimbolkan menggunakan padi dan palawija yang implikasinya seperti mengembangkan karakter demokrasi, persahabatan dan ketenangan pikiran.

\section{METODA}

Peneliti menggunakan metode penelitian kualitatif. Penelitian ini dilakukan di Kabupaten Banyumas terhadap pelaku tradisi begalan yang berasal dari sanggar Sekar Kantil di Kecamatan Sumbang, Kabupaten Banyumas. Fokus penelitian ini adalah pemaknaan tradisi begalan yang diberikan oleh sanggar Sekar Kantil terhadap tradisi begalan dan makna dari ubo rampe dalam pelaksanaan tradisi begalan. Data penelitian ini berupa data primer dan data sekunder. Data primer diperoleh dengan observasi, wawancara dan pemanfaatan dokumen foto yang berkaitan dengan pelaksanaan tradisi begalan yang dilakukan oleh sanggar Sekar Kantil dan pemaknaan tradisi begalan yang diberikan oleh sanggar Sekar Kantil, sedangkan data sekunder diperoleh melalui kajian sumber pustaka tertulis dan foto yang berhubungan dengan fokus penelitian. Subjek dalam penelitian ini adalah pelaku tradisi begalan dari sanggar Sekar Kantil, pengguna tradisi begalan, dan penonton tradisi begalan.

\section{HASIL DAN PEMBAHASAN}

\section{A. Gambaran Umum Sanggar Sekar Kantil}

Sanggar Sekar Kantil adalah sebuah sanggar yang ada di Desa Kedungmalang, Kecamatan Sumbang, Kabupaten Banyumas, Jawa Tengah. Sanggar Sekar Kantil berdiri pada tanggal 5 April 2010 oleh Wahyu Limanto seorang pelaku tradisi begalan yang ada di Kabupaten Banyumas. Keberadaan Sanggar Sekar Kantil adalah sebuah harapan dan cita-cita yang telah terwujud dari Wahyu Limanto untuk bisa menyediakan tempat bagi siapa saja yang ingin mempelajari dan nguriuri kebudayaan Jawa khususnya yang ada di Banyumas berupa seni tari, begalan, dan pranotocoro.

Lokasi yang saat ini menjadi sanggar Sekar Kantil adalah rumah peninggalan dari keluarga pelawak yang terkenal pada era 1970an - 1990an yaitu grup lawak "Peyang Penjol". Rumah yang menjadi menjadi tempat berkumpul keluarga pelawak Peyang Penjol dijadikan sebagai sanggar oleh mas Wahyu Limanto atas izin keluarga yang juga sekaligus mendukung bahwa ada keturunan mbah Peyang sebagai pelaku tradisi begalan. Selain Wahyu terdapat juga anak dari mbah Peyang yang menjadi pelaku tradisi begalan yaitu pak Saparilek yang juga partner kerja dari Wahyu. Peyang Penjol merupakan salah satu grup lawak asli Banyumas yang banyak dikenal oleh masyarakat Banyumas.

Rumah yang menjadi sanggar Sekar Kantil dapat dipetakan menjadi tiga lokasi yang berbeda dengan fungsinya masingmasing. Bagian depan sanggar digunakan sebagai garasi dan tempat untuk menyimpan berbagai peralatan yang bisa digunakan dalam setiap penampilan anggota. Bagian tengah rumah merupakan rumah utama dari keluarga pengasuh sanggar, terdapat empat kamar tidur, dapur, ruang tamu, ruang makan dan ruang keluarga. Bagian belakang rumah terdapat sebuah ruangan yang digunakan oleh seluruh anggota sanggar untuk berkumpul, berdiskusi dan berlatih.

Keanggotaan sanggar Sekar Kantil tidak mengikat, namun terdapat ketentuan khusus yang ditawarkan kepada calon anggota sanggar sebelum bergabung. Ketentuan tersebut bahwa setiap orang yang akan menjadi anggota sanggar diharuskan membayar "EMAS dan DUIT". EMAS dan DUIT dalam hal ini bukan sebuah bentuk yang nyata dari emas yang berasal dari logam mulia dan duit atau uang yang digunakan oleh masyarakat sebagai alat pertukaran, melainkan sebuah singkatan. EMAS berarti eling manunggaling sabar dan DUIT berarti Doa Ikhtiar Usaha dan Tanggung-jawab. Doa Ikhtiar Usaha dan Tanggung-jawab itu menjadi pedoman dalam menjalani kehidupan sehari-hari dan kehidupan belajar di sanggar Sekar Kantil. Aturan mengenai EMAS dan DUIT tidak secara tertulis dalam peraturan sanggar, melainkan diberikan secara lisan oleh pengasuh kepada anggota-anggota sanggar. EMAS dimaksudkan untuk senantiasa mengingat kepada tujuan awal ketika masuk ke sanggar dan senantiasa ingat kepada Tuhan, guru-guru dan keluarga. DUIT mengandung makna bahwa ketika dalam menuntut ilmu di sanggar senantiasa berdoa dan berikhtiar kepada Tuhan dan selalu 
bertanggung-jawab terhadap apa yang dikerjakan juga tidak mudah tergiur dengan hal-hal yang bukan merupakan tanggung-jawabnya. Penanaman syarat EMAS dan DUIT kepada anggota sanggar dilakukan oleh pengasuh sanggar untuk menumbuhkan kesadaran dan kecintaan terhadap sanggar dan ilmu yang didapatkan di sanggar. Sehingga diharapkan setiap anggota menyadari tentang pentingnya kebersamaan dan kekeluargaan dalam sanggar.

\section{B. Kegiatan Sanggar Sekar Kantil}

Sanggar sekar kantil memiliki kegiatan rutin dan tidak rutin. Kegiatan tersebut dimaksudkan untuk menjalin silaturahmi dan mempererat persaudaraan sesama anggotanya. Kegiatan yang dilaksanakan secara tidak rutin adalah pertemuan mendadak untuk membahas sebuah acara dan juga latihan yang menyesuaikan jadwal kesibukan anggota sanggar. Karena setiap anggota memiliki kesibukan tersendiri kadang-kadang ada anggota sanggar yang khusus datang menemui pengasuh sanggar untuk berlatih tradisi begalan atau tembang-tembang atau dalam bahasa Indonesia merupakan lagu-lagu yang akan digunakan dalam tradisi pernikahan sebagai hiburan.

Kegiatan yang rutin dilaksanakan setiap bulan adalah pertemuan yang diadakan setiap malam Jumat Kliwon dan malam Selasa Kliwon. Kegiatan yang wajib dilaksanakan setiap malam Selasa Kliwondan Jumat Kliwon adalah melaksanakan tawasulan atau yang biasa kita kenal dengan tahlilan dan kidungan. Pada bulan Suro perwakilan anggota sanggar Sekar Kantil akan pergi ke Mojokerto menghadiri acara mangesti suro bumi Majapahit di Pendopo Agung Trowulan Mojokerto. Selain menghadiri acara tersebut kegiatan mengunjungi kota Mojokerto juga digunakan pengasuh sanggar untuk memperkenalkan kebudayaan Jawa dan Majapahit yang ada di kota Mojokerto dan sekitarnya. Tujuan lain dari diadakannya acara tersebut juga sekaligus untuk merekatkan tali persaudaraan antara anggota sanggar Sekar Kantil dan anggota sanggar yang ada di Mojokerto.

Kegiatan yang selanjutnya diadakan oleh sanggar Sekar Kantil adalah ikut berpartisipasi dalam kegiatan paguyuban atau komunitas yang ada di Kabupaten Banyumas. Ter- dapat beberapa acara yang diikuti oleh sanggar Sekar Kantil untuk lebih dikenal oleh masyarakat luas. Seperti yang diikuti oleh sanggar Sekar Kantil pada tahun 2019 saat penelitian ini dilakukan, yaitu mengikuti pementasan seni pada paguyuban cucuk lampah Banyumas "Pucung Mas". Dalam pertemuan yang dilakukan oleh Wahyu dengan pelaku cucuk lampah lainnya, selain mengadakan pementasan seni juga saling berinteraksi dan berkomunikasi dalam hal cucuk lampah dan tradisi pernikahan.

\section{Pelaksanaan Tradisi Begalan}

Tradisi begalan memiliki sebuah arti kebegalan sambikalanipun yang memiliki maksud untuk dijauhkan dari segala marabahaya. Tradisi begalan merupakan penggambaran dari peristiwa yang terjadi pada masa lalu di Karesidenan Banyumas berupa perampokan terhadap barang bawaan dari rombongan pengantin pria oleh begal. Begal artinya sama dengan perampok yaitu orang yang pekerjaanya berbuat kriminal dengan merampas barang milik orang lain. Begal yang merampas barang milik orang lain digunakan dalam tradisi begalan sebagai perumpamaan saja, tidak merebut barang dalam arti sesungguhnya. Tetapi merampas waktu milik pengantin yang akan naik pelaminan untuk memberikan nasehat dan tuntunan kepada pengantin baru tentang kehidupan berumahtangga.

Tradisi begalan sudah ada sejak zaman Adipati Wirasaba yang pada saat itu akan menikahkan putri bungsunya, Dewi Sukesi dengan Tirtokencono putra Sulung Adipati Banyumas. Setelah dilaksanakan pernikahan, Adipati Banyumas berniat untuk membawa putra dan menantunya dari Wirasaba ke Banyumas atau dalam bahasa Jawa disebut ngunduh manten. Acara tersebut dilakukan seminggu setelah akad nikah Dewi Sukesi dan Tirtokencono. Ketika masuk ke dalam kawasan hutan belantara rombongan tiba-tiba dihentikan oleh beberapa orang yang menggunakan pakaian serba hitam dengan menggunakan ikat kepala dan terselip golok di pinggang mereka. Orang yang berpakaian serba hitam tersebut bermaksud untuk merampas semua barang bawaan yang dibawa oleh rombongan pengantin. Namun begal 
tersebut berhasil dikalahkan oleh para pengawal Adipati Banyumas dan lari tunggang langgang dengan tangan kosong. Peristiwa ini menjadi inspirasi tradisi begalan yang masih hidup di tengah masyarakat.

Tradisi begalan yang dilakukan oleh sanggar Sekar Kantil pada setiap penampilannya terdapat dua tahapan. Pertama adalah tahap persiapan dimana pelaku tradisi begalan menyiapkan segala kebutuhan dan keperluan yang akan digunakan dalam penampilan. Kedua adalah tahap pelaksanaan, dimana merupakan puncak acara dan acara inti dalam tradisi begalan yang ada dalam pernikahan masyarakat Banyumas.

\section{Persiapan}

Persiapan dilakukan dari sebelum berangkat ke lokasi tempat pertunjukan yaitu dengan memesan ubo rampe yang akan digunakan. Pelaku tradisi bagalan akan mempersiapkan ubo rampe, kostum, make up, tempat yang akan digunakan dan juga gendhing-gendhing yang akan digunakan untuk pelaksanaan tradisi begalan begitu sampai di lokasi pernikahan.

Kostum dan make up disesuaikan dengan peran masing-masing pelaku tradisi begalan. Wahyu sebagai danabau atau yang menjadi utusan keluarga pengantin perempuan akan berdandan rapi dengan riasan di wajah, baju rapi dan menggunakan jarit serta sandal selop. Sedangkan pak Saparilek sebagai juru mertani atau sebagai perampok akan menggunakan dandanan seadanya dengan riasan kumis palsu dan membawa senjata kudi yang terbuat dari papan kayu yang dicat sedemikian rupa hingga sama dengan kudi asli.

Ubo rampe dan kendhil yang telah ada kemudian dirangkai sedemikian rupa pada pikulan sehingga menjadi sebuah ubo rampe yang utuh. Terdapat 12 macam peralatan rumah-tangga tradisional yang digunakan untuk membuat sebuah ubo rampe dalam tradisi begalan yaitu pikulan, ilir, cething, iyan kusan, siwur, sorok, ciri, munthu, irus, sapu sada, dan kendhil. Semua alat rumah tangga yang telah disebutkan sebelumnya ditempatkan pada pikulan bagian kanan dan kiri agar supaya seimbang.

\section{E. Pelaksanaan}

Tradisi begalan diadakan di tempat acara pernikahan pada masyarakat Banyumas yang biasanya mengadakan pernikahan di rumah mempelai wanita. Tradisi begalan dapat dilaksanakan dimanapun asalkan terdapat tempat yang cukup untuk meletakan ubo rampe yang dibawa. Lokasi yang akan digunakan harus pada tempat yang dapat dilihat oleh banyak orang, juga oleh pengantin dan tamu undangan. Sebab sasaran pelaksanaan tradisi begalan bukan hanya pasangan pengantin yang baru saja menikah namun juga pasangan suami-istri yang sudah lama menikah untuk mengingatkan kembali petuah dan nasehat dalam kehidupan rumah-tangga. Lokasi yang dipilih adalah di antara pelaminan dan penonton.

Pelaksanaan tradisi begalan dilaksanakan setelah pelaksanan ijab qobul oleh penghulu dan sebelum pengantin memasuki pelaminan. Tradisi begalan akan merampas waktu milik pengantin sebelum masuk ke pelaminan sebagai syarat atau krewah untuk membuang bajang sawan kaki nini penganten terhadap pernikahan anak tertentu pada masyarakat Banyumas. Tradisi begalan selain digunakan sebgaai sarana untuk membuang bajang sawan kaki nini penganten, juga memiliki tujuan agar pasangan pengantin baru terhindar dari hal-hal yang tidak diinginkan, khususnya dari gangguan gaib.

Tradisi begalan dimainkan oleh dua orang yang masing-masing memiliki peran tersendiri. Satu orang menjadi tokoh danabau yang merupakan utusan dari pengantin lakilaki, dan tokoh juru mertani yang berperan sebagai penjahat yang diutus oleh keluarga pengantin perempuan untuk menjaga wilayah sekitar tempat berlangsungnya acara. Acara akan dimulai ketika pranotocoro mulai memutarkan gending-gending yang digunakan sebagai lagu tanda dimulainya tradisi begalan. Pelaku tradisi begalan akan masuk menggunakan tari-tarian dan akan berhenti menari ketika gending yang diputar berhenti. Salah satu pelaku tradisi begalan akan memperkenalkan diri sebagai ucapan pembukaan.

Setelah mengungkapkan kata pembuka dan pada akhir ucapan "sumonggo kulo nyuwun iringanipun" yang memiliki arti untuk memberikan sebuah peringatan kepada tukang 
sound untuk memutarkan gending-gending Banyumasan agar kedua pelaku tradisi begalan dapat menari lagi didepan penonton dan akan memulai tradisi begalan. Pelaku tradisi begalan tidak hanya menjelaskan mengenai ubo rampe yang dibawa juru mertani dan danabau juga banyak memberikan lawakan-lawakan yang membuat geli para tamu undangan. Setelah menjelaskan semua uborampe yang dibawa kemudian Wahyu mengambil kendhil yang ada dipikulan untuk diberikan kepada kedua mempelai, Wahyu dan Saparilek membacakan doa. Saparilek kemudian memberikan uborampe yang dibawanya kepada para tamu undangan yang hadir untuk diperebutkan seluruhnya kecuali pikulannya.

Inti dari dialog yang disampaikan oleh Juru mertani dan Danabau berisi mengenai nasehat dan petuah yang diberikan kepada pengantin baru melalui makna-makna yang terdapat dalam ubo rampe yang dibawa dan dijelaskan oleh kedua pelaku tradisi begalan. Pelaksanaan tradisi begalan dalam pelaksanaannya menggunakan bahasa daerah (Jawa) yang telah dipahami oleh masyarakat Banyumas.

\section{F. Redefinisi Makna Tradisi Begalan \\ 1. Pemaknaan Tradisi Begalan oleh Sanggar Sekar Kantil}

Masyarakat Banyumas meyakini tradisi begalan menjadi simbol pemberian nasehat dan bekal dari para keluarga kepada calon pengantin yang akan menjalani hidup baru. Karena dinilai memiliki arti penting. Begalan berfungsi sebagai sarana untuk memberikan pengetahuan dan nilai, khususnya nilai-nilai Jawa Banyumasan yang santun, toleran, kerja keras, komitmen, setia kawan, dan penghargaan terhadap orang lain. Nilai-nilai Jawa Banyumasan ini dikemas dan disimbolkan dalam ubo rampe. Peralatan itu mempunyai makna-makna yang bisa diuraikan oleh pelaku tradisi begalan dari sanggar Sekar Kantil. Begalan juga mengingatkan pengantin-pengantin lawas (lama) akan nilai-nilai luhur Banyumas. Dari keseluruhan penjelasan tersebut, kesenian begalan bukan semata-mata merupakan suatu pertunjukan saja atau untuk hiburan namun juga sebagai tontonan yang bermutu, serta bernilai tinggi, sebab di dalam kesenian begalan terdapat dialog yang isinya memberi ajaran atau tuntunan, khususnya ditujukan pada mempelai dan masyarakat pada umumnya. Peristiwa begalan ini bisa dianalisis dengan perspektif antropologi fenomenologi.

Dikatakan oleh Laughlin (dalam Hamdanah, 2005) bahwa antropologi fenomenologis adalah antropologi yang mempelajari tentang kesadaran sosial, bukan kesadaran individu. Kesadaran sosial merupakan kesadaran tentang sesuatu hal yang melibatkan banyak orang atau mencakup banyak orang bukan hanya individu. Kesadaran kolektif yang terbangun memiliki makna yang sama dengan kebudayaan dalam antropologi, dimana kebudayaan tidak lain adalah seperangkat pengetahuan yang merupakan hasil dari proses belajar yang didapatkan melalui perantara bahasa dan komunikasi antar pemilik kebudayaan. Pemaknaan yang diberikan oleh sanggar Sekar Kantil kepada tradisi begalan merupakan sebuah pengetahuan seluruh anggota sanggar Sekar Kantil yang didapatkan dari proses belajar di sanggar Sekar Kantil. Setiap pelaku tradisi begalan dapat memberikan makna kepada tradisi begalan namun hanya menjadi pengetahuan individu karena hanya pelaku tersebut saja yang memiliki pemakanaan terhadap tradisi begalan. Berbeda dengan sanggar Sekar Kantil yang setiap anggota diberikan pengetahuan dan diharapkan untuk dapat memaknai dan menghayati setiap makna yang terdapat dalam tradisi begalan sehingga dalam pelaksanaan tradisi begalan tidak ada selisih paham antaranggota.

Begalan berasal dari kata "begal" dan akhiran "an" yang menurut Herususanto (2008: 235) begal artinya sama dengan perampok atau perampas, sedangkan "mbegal" = "merampok", yaitu orang yang pekerjaanya merampas barang milik orang lain. Istilah begalan dalam tradisi pernikahan masyarakat Banyumas bukan berarti merampas atau merebut barang milik orang lain, tetapi lebih untuk menjaga atau mempertahankan keselamatan apabila terdapat roh-roh jahat yang datang untuk mengganggu jalannya upacara pernikahan. Begalan juga diartikan sebagai perampasan waktu milik pengantin sebelum keduanya bersanding dipelaminan dengan tujuan untuk mendapatkan pengetahuan dan 
nasehat yang berguna untuk kehidupan rumah tangga mereka kedepan.

Sanggar Sekar Kantil memiliki pemaknaan tersendiri mengenai tradisi begalan. Tradisi begalan diartikan sebagai sebuah acara pertunjukan seni dalam pernikahan yang berasal dari cerita rakyat tentang adipati Banyumas. Begalan diartikan sebagai besan gawa lantaran. Besan gawa lantaran memiliki maksud bahwa ketika seorang laki-laki akan menikahi seorang anak perempuan, ia harus membawa lantaran untuk menunjukan keseriusannya dalam menikahi anak perempuan tersebut kepada orang-tua dan keluarga perempuan. Sehingga keluarga perempuan mau menerima calon pengantin laki-laki karena melihat kesungguhannya dari lantaran yang dibawa. Pemberian makna baru terhadap tradisi begalan oleh sanggar Sekar Kantil tidak semata-mata berubah tanpa sebab.

Pemaknaan yang diberikan telah melalui proses yang panjang dari pelaku tradisi begalan dari sanggar Sekar Kantil. Pengalaman yang lama dalam dunia pernikahan adat Banyumas khususnya tradisi begalan dan juga pengalaman yang didapatkan dari pelaku tradisi begalan sebelumnya memberikan pengetahuan yang berbeda dari setiap generasi. Meskipun awalnya muncul pro dan kontra namun pelaku tradisi begalan dari sanggar Sekar Kantil berusaha mempertahankan dan meyakinkan kepada pelaku tradisi begalan lainnya. Pemaknaan yang kemudian diturunkan kepada anggota sanggar Sekar Kantil akan digunakan pada setiap pelaksanaan tradisi begalan dengan harapan bahwa masyarakat mau menerima dengan pemaknaan yang diberikan oleh sanggar Sekar Kantil bahwa begalan diartikan sebagai besan gawa lantaran yang bukan lagi tentang proses perampokan oleh begal.

Terdapat beberapa sebutan yang digunakan dalam pelaksanaan tradisi begalan oleh pelaku tradisi begalan, tidak ada kesepakatan khusus mengenai penggunaan sebutan bagi pelaku dalam melaksanakan tradisi begalan disesuaikan dengan pengetahuan dan kepercayaan setiap pelaku tradisi begalan karena penggunaan nama tersebut memiliki makna tersendiri bagi pelaku tradisi begalan. Sanggar Sekar Kantil memiliki nama sebutan tersendiri bagi pelaku tradisi begalan dalam pelaksana- annya. Nama yang digunakan memiliki makna dan arti tersendiri bagi anggota sanggar. Sebutan yang digunakan bagi pelaku tradisi begalan adalah Danabau dan Juru mertani. Danabau dimaknai sebagai wong sing sok paring "weweh" bauning tenaga, dalam bahasa Indonesia danabau itu adalah orang yang ringan tangan, orang yang suka membantu siapa saja yang membutuhkan bantuan. Sedangkan Juru mertani merupakan orang yang sedang diutus pihak pengantin putri untuk menjaga kawasan atau lingkungan tempat tinggal pengantin putri.

Tradisi begalan berkaitan dengan kepercayaan masyarakat Banyumas mengenai gangguan yang berasal dari kekuatan-kekuatan gaib diluar kendali dari diri mereka. Pada pelaksanaan tradisi begalan dipercaya oleh pela$\mathrm{ku}$ tradisi begalan dan masyarakat Banyumas bahwa bajang sawan nini penganten karo kaki penganten berada atau bertempat di dalam kendil yang ada dalam ubo rampe begalan, sehingga perlu dipecahkan untuk membuang kekuatan gaib tersebut. Sedangkan dalam pelaksanaan tradisi begalan yang dilakukan oleh sanggar Sekar Kantil, pelaku tradisi begalan tidak memecahkan kendil karena menganggap bahwa bajang sawan tidak berada di dalam kendil dan bisa berada di mana saja tidak hanya di dalam kendil.

Bajang sawan adalah hal gaib yang dipercayai bertempat di dalam kendil yang dapat membuat rumah-tangga pengantin baru akan mendapatkan bahaya sehingga perlu dipecahkan atau dihancurkan agar supaya tidak ada marabahaya yang dapat menghampiri pengantin baru. Pelaku tradisi begalan dari sanggar Sekar Kantil percaya kendil yang tidak dipecah memiliki fungsi yang lebih banyak daripada ketika dipecahkan. Kegunaan kendil yang pertama adalah isi kendil yang berupa uang receh, beras kuning, dan bumbu dapur atau sambetan. Uang receh dapat digunakan untuk beramal kepada orang lain terutama anak-anak kecil yang datang ke acara pernikahan. Beras kuning dapat dimasak menjadi makanan yang bernama golong (nasi berbahan dasar beras kuning yang dikepalkepal) untuk dimakan oleh pengantin berdua setelah selesai acara pernikahan. Kemudian bumbu dapur dapat digunakan nanti ketika pengantin perempuan akan memasak masakan 
untuk suaminya. Sedangkan untuk kendilnya dapat disimpan untuk dijadikan tempat ari-ari (placenta) ketika pasangan pengantin itu nanti memiliki anak.

Pro dan kontra bermunculan ketika pelaku tradisi begalan dari sanggar Sekar Kantil mulai menerapkan bahwa ketika pelaksanaan tradisi begalan kendilnya tidak dipecah. Pengetahuan secara umum bahwa pada tradisi begalan yang lain, kendil yang ada dalam ubo rampe harus dipecah karena terdapat bajang sawan yang dipercaya bisa mendatangkan hal-hal yang buruk kepada pengantin baru. Menurut pelaku tradisi begalan dari sanggar Sekar Kantil tetap ada yang dipecah dalam tradisi begalan meskipun bukan kendil, melainkan pemikiran kedua pengantin yang sudah pecah menjadi lebih dewasa dan tidak kekanak-kanakan lagi. Untuk bajang sawan bisa bertempat di mana saja dan yang memiliki kuasa untuk menghilangkannya adalah Tuhan, sehingga pelaku tradisi begalan dari sanggar Sekar Kantil berdoa kepada Tuhan Yang Maha Esa untuk kelangsungan rumah-tangga pengantin baru tersebut supaya tidak ada yang menggoda atau menggangu rumah-tangga pengantin yang baru saja menikah.

\section{G. Pemaknaan Ubo Rampe Tradisi Begalan oleh Sanggar Sekar Kantil}

Tradisi begalan dalam pelaksanaannya menggunakan berbagai macam peralatan rumah-tangga yang masing-masing memiliki makna tersendiri bagi kehidupan rumahtangga. Peralatan yang digunakan dalam tradisi begalan dinamakan ubo rampe. Makna yang terdapat dalam ubo rampe dijelaskan oleh pelaku tradisi begalan sesuai dengan latar belakang, pengetahuan dan pengalaman yang telah didapatkan sebelumnya. Saddhono dan Kuniawan (2016) menjelaskan ubo rampe yang terdapat dalam tradisi begalan merupakan jenis peralatan dapur yang memuat mengenai nasihat, pitutur dan pituduh untuk pengantin dan penonton pada acara pernikahan.

Menurut Ahimsa-Putra (2012:281), fenomenologi memandang manusia sebagai makhluk yang memiliki kesadaran mengenai sesuatu. Memahami kesadaran yang diperoleh melalui "refleksi", melalui pikiran yang berupa memikirkan dirinya sendiri, memikirkan, menyadari, tentang "pikiran" itu sendiri. Sehingga kesadaran mengenai sesuatu tersebut merupakan sebuah pengetahuan. Pelaku tradisi begalan dari sanggar Sekar Kantil memiliki pemaknaan tersendiri terhadap ubo rampe begalan yang didapatkan dari pengalaman dengan pengalaman yang tidak sedikit dan juga telah bertemu dengan banyak dukun penganten, mengambil kesimpulan dari pengalaman-pengalaman sebelumnya bahwa tradisi begalan sebelumnya memerlukan banyak waktu dan membosankan karena pelaku tradisi begalan hanya berdialog dengan pelaku tradisi begalan lainnya tanpa bisa menghidupkan suasana sehingga terkesan membosankan.

Inovasi yang diberikan dalam tradisi begalan adalah dengan cara menjelaskan $u b o$ rampe tradisi begalan menggunakan sanepan atau othak-athik gathuk atau gothak-gathik gathuk. Sanepa atau yang dalam bahasa Jawa disebut gotak gatik gatuk atau dalam bahasa Indonesia merupakan aktivitas berpikir mencocogkan berbagai hal sehingga menjadi sesuatu yang saling berhubungan. Ubo rampe tradisi begalan dijelaskan menggunakan sanepan untuk mempermudah dalam menjelaskan dan tidak membuang waktu terlalu banyak. Penggunaan sanepan atau gotak gatik gatuk tersebut menjadikan makna dari ubo rampe yang sebelumnya dijelaskan satu persatu sesuai dengan bentuk alat rumah tangga berubah menjadi beberapa ubo rampe dijelaskan dalam satu makna. Seperti pada pelaksanaan tradisi begalan sebelumnya atau dari pelaku tradisi begalan yang berasal dari luar sanggar Sekar Kantil akan menjelaskan makna dari pikulan tersendiri kemudian dilanjutkan makna dari iyan, ilir, kusan, dan lain sebagainya. Sedangkan dalam pelaksanaan tradisi begalan yang dilakukan oleh sanggar Sekar Kantil menggunakan sanepan atau gothak gathik gathuk seperti alat yang digunakan untuk membuat lauk yaitu ciri, munthu, irus yang melambangkan manunggaling rasa yang dalam bahasa Indonesia merupakan "rasa berbeda-beda jadi satu". Penggunaan sanepan dalam pelaksanaan tradisi begalan juga memudahkan pelaku tradisi begalan dari sanggar Sekar Kantil untuk membuat lawakan atau dagelan yang dapat menghibur penonton yang 
hadir. Hal itu dimaksudkan untuk menghibur dan mencairkan suasana pernikahan.

\section{SIMPULAN}

Pelaksanaan tradisi begalan yang dilakukan oleh sanggar Sekar Kantil memiliki dua tahapan dalam pelaksanaanya yaitu persiapan dan pelaksanaan. Pada tahap persiapan pelaku tradisi begalan mempersiapkan segala hal yang dibutuhkan untuk pelaksanaan tradisi begalan.

Redefinisi makna tradisi begalan merupakan pemaknaan ulang yang diberikan oleh sanggar Sekar Kantil terhadap arti tradisi begalan, nama pelaku tradisi dan tentang bajang sawan. Tradisi begalan berasal dari kata begalan yang memiliki arti besan gawan lantaran, lantaran yang menunjukan keseriusannya dalam menikahi anak perempuan dengan membawa barang-barang untuk pengantin perempuan. Sanggar Sekar Kantil menggunakan sebutan nama Danabau dan Jurumertani untuk pelaku dalam pelaksanaan tradisi begalan. Penjelasan ubo rampe tradisi begalan yang dilaksanakan oleh sanggar Sekar kantil adalah dengan menggunakan sanepan atau othak athik gathuk. Sanepan atau perumpamaan yang dalam bahasa Jawa disebut othak athik gathuk merupakan cara berpikir dengan menghubungkan berbagai hal sehingga terasa wajar, relevan dan signifikan. Pemberian makna yang dilakukan oleh pengasuh sanggar Sekar Kantil dan dipahamkan kepada anggota sanggar menimbulkan kesadaran subjektif. Pemaknaan di sini dapat disebut sebagai pegetahuan (cultural knowledge) karena telah menjadi pengetahuan umum anggota sanggar yang kemudian mereka sebarluaskan dalam setiap pertunjukan.

Bagi anggota sanggar Sekar Kantil dapat memanfaatkan ilmu yang didapat dari menjadi anggota sanggar sehingga bisa menjadi lapangan pekerjaan yang dapat dijadikan mata pencaharian alternatif dan juga dapat mengadakan pementasan seni sehingga dapat menarik generasi muda yang lebih banyak untuk mempelajari kebudayaan Jawa Banyumas khususnya tradisi begalan. Bagi kantor dinas pemerintah yang mempunyai wewenang, hendaknya melakukan tinjauan kepada sanggar-sanggar seni yang ada dan kesenian yang ada di Kabupaten Banyumas agar dapat menjaga kelestariannya dan tetap hidup di tengah masyarakat.

\section{DAFTAR PUSTAKA}

Ahimsa-Putra, Heddy Shri. 2001. Strukturalisme Levi-Strauss Mitos Dan Karya Sastra. Yogyakarta: Galang Press.

Brata, Nugroho Trisnu. 2008. PT. Freeport \& Tanah Adat Kamoro Kajian TeoriTeori Antropologi. Semarang: UNNES PRESS.

Brata, Ida Bagus. 2016. Kearifan Budaya Lokal Perekat Identitas Bangsa. Jurnal Bakti Saraswati. ISSN: 2088-2149, Vol. 05 No.1. Meret 2016.

Fitriani, Rina. 2012. Peranan Paguyuban Tionghoa Purbalingga dalam Pelestarian Tradisi Cap Go Meh. Jurnal Komunitas. Komunitas Volume 4 Nomor 1, hal. 73-81. ISSN : 2086-5465

Geertz, Hildred. 1985. Keluarga Jawa.Jakarta: PT Temprint.

Hamdanah. 2005. Musim Kawin di Musim Kemarau Studi Atas Pandangan Ulama Perempuan Jember tentang Hak-Hak Reprodusksi Perempuan. Yogyakarta: BIGRAF Publishing bekerja sama dengan Yayasan Adhikarya IKAPI dan The Ford Foundation.

Herususanto, Budiono. 2008. BANYUMAS: Sejarah, Budaya, Bahasa, dan Watak. Yogyakarta: LKIS Yogyakarta.

Karyono. 2009. Tari Begalan di Tengah Perubahan Sosial Masyarakat Banyumas. Jurnal ISI Surakarta. Volume 8 Nomor 1.

Kholifah, Asrofin Nur. 2018. Rendering Cultural Elements in Banyumas Begalan: A Translation Studies Perspective. Jurnal Ilmiah Lingua Idea. Volume 9 Nomor 2. ISSN 25801066.

Kurnianingsih, Yunika Susila dan Nugroho Trisnu Brata.2015. Tradisi Ngenger dalam Konteks Bride Service pada Masyarakat Jawa di Desa Botoreco Kecamatan Kunduran Kabupaten Blora. Jurnal Solidarity. Volume 4 Nomor 1. ISSN 2252-7133.

Laksono. P. M. 2009. Tradisi dalam Struktur Masyarakat Jawa Kerajaan dan 
Pedesaan Alih Ubah Model Berpikir Jawa. Yogyakarta: Kepel Press.

Newberry, Jan. 2013. Back Door Java: Negara, Rumah Tangga dan Kampung di Keluarga Jawa. Jakarta : KITLV dan Yayasan Pustaka Obor Indonesia.

Priyanto, Wien Pudji. 2008. Nilai Nilai Pendidikan dalam Seni Tutur Begalan di Banyumas. Jurnal Cakrawala Pendidikan Universitas Negeri Yogyakarta. Juni, Th. XXVII, No. 2.

Saddhono, Kundharu dan Alfa Kurniawan. 2017. Islamic Religious Value in Traditional Ceremony of Begalan Banyumasan as Education Character for Student at Senior High School in central Java. Jurnal UMRAN International Journal of Islamic and
Civilizational Studies. Volume 4 Nomor 1. pp. 71-77.

Suroso, Eko, Kundharu Sudhono dan Sumarlan. 2018. The Implicature of Begalan Tradition as An Effort to Develop a Good Character in The Community in Banyumas Central Java. Artikel dalam 5th International Conference on Community Development (AMCA 2018) . Advance in Social Science, Education and Humanities research, Volume 231. pp. 278-280.

Utami, Novi Widiya. 2016. Wujud Kebudayaan dalam Prosesi Baradok Ritual Adat Pernikahan Sumbawa. Jurnal Retorika.Volume 9 Nomor 2 Agustus, hal. 90-163. 